\title{
THE IMPACT OF COST OF LIVING DIFFERENTIALS ON MIGRATION OF ELDERLY PEOPLE TO FLORIDA
}

\author{
David W. Rasmussen, Gary M. Fournier, and Douglas A. Charity*
}

The research reported here was supported by the Florida House Appropriations Committee under the STAR program, Project Grant Number 87-054. This paper was presented at the Southern Regional Science Association meeting in Morgantown, West Virginia, April 14-16, 1988.

\section{Introduction}

Migration patterns of the growing elderly population can have important effects on the economic vitality of regions. In places that receive a disproportionate share of the elderly, such as areas in Florida, Arizona, and California, migration can have magnified effects on the economic base, housing market, infrastructure needs, and social service delivery systems in the region. Local governments typically face the task of anticipating these effects, but are handicapped by a lack of understanding of the migration of elderly people. In this paper the determinants of such migration are analyzed with special reference to how cost of living influences the selection of a destination by migrating elderly persons (55 and over) during 1975-1980.

The results of the study support the hypothesis that cost of living differentials provide the elderly an incentive to move that is not unlike the incentive wage differentials provide members of the labor force. The results indicate that cost of living differentials among groups of Florida counties have a major impact on the migration decisions of elderly households. This conclusion applies even after taking into account the effects of amenities.

Some recent research is surveyed in the next section, and some analyses of elderly migration are presented in Sections 3 and 4. The implications of the findings are elaborated further in the last section.

\section{Previous Research}

Economists typically explain inter-area variations in net migration on the basis of spatial differentials in labor markets and related measures of the relative economic well being of the areas. In its most general expression, human

"Professor of Economics and Policy Sciences, Associate Professor of Economics, and Graduate Student in Economics and Demography, Florida State University, Tallahassee, FL 32306 capital theory argues that an individual will migrate when the expected benefits outweigh the costs. For example, migration by people who continue to participate in the labor force has been shown to be heavily influenced by wage differentials and the probability of employment (Morgan and Robb, 1981; Greenwood et. al., 1986).

Migration among retirees is an important component of population mobility that is not related clearly or directly to labor market considerations. Empirical studies attempting to explain this phenomenon have employed three types of variables: those associated with the gravity model, amenity or quality of life variables, and economic factors. ${ }^{1}$ The gravity model relies on the expectation that the flow of migrants between any two states will be positively related to the size of the population at both the origin and destination and inversely related to the distance between the two points.

Amenity and "quality of life" factors are difficult to measure and of dubious validity at the state level. The most obvious difficulty in measurement is the implicit assumption that an average value for the state accurately reflects the extent to which the amenity is available to all state residents. Rives et. al. (1983), McLeod et. al. (1984) and Fournier et. al. (1988) attempt to capture quality of life with crime rates, availability of health care, and climate. Other studies have used environmental pollution (Cebula, 1979), measures of recreation services (Barsby and Cox, 1975; Cebula, 1979), and the proximity of lakes and coasts (Fournier et. al., 1988).

Economic variables such as income do not always appear to be dominant in the migration decisions of the elderly (Heaton et. al., 1981). Indeed, Cebula (1979) found mixed evidence on economic variables; income was not a significant determinant of net migration of the elderly but the level of state and local taxes had a significant negative impact. Rives et. al. (1983) and McLeod et. al. (1984) point out that all the economic variables in these models approximate the effects of cost of living variations, an observation that seems particularly apropos for variables such as housing costs (McLeod et al., 1984) and taxes (Alm, 1982). Fournier et. al. (1988) tested the hypothesis that cost of living variations among states provide an inducement for the elderly to migrate. Using the BLS budget surveys for retired couples, they created an index for interstate comparison of the cost of living for elderly couples. This cost 
of living index was a highly significant determinant of the flow of migrants between states in a model that also included amenity variables and elements of the gravity model.

Although Fournier et. al.(1988) were able to provide actual cost of living estimates to replace of the proxy variables used in other studies, the limitations inherent in the use of statewide amenity variables remain a problem. Recognizing this dificiency in the data, the authors present several regressions using alternative measures of quality of life to see if the significance of the cost of living variable is sensitive to the specification of the amenity variables. The importance of cost of living was unaffected by these changes in specification.

This paper summarizes a study of the impact of geographic cost of living differentials on the flow of elderly migrants from 48 states to 31 groups of Florida counties. The factors that determine the distribution of elderly migrants among the alternative destination also were analyzed. The availability of an index of cost of living for Florida counties offers the opportunity to measure cost of living at the destination more precisely than in previous research. Perhaps more important is that county data permit much better estimates of the amenity characteristics of alternative destinations.

\section{The Flow of Elderly Migrants to Florida: $1975-1980$}

The migration data used in this study were extracted from the five percent file of the 1980 Public Use Microdata Sample. This file contains the record of each person who reported having changed county of residence between 1975 and 1980. In this section, a regression analysis of the flow of elderly migrants from the other 47 contiguous states to 31 county groups in Florida is presented ${ }^{2}$. Alaska and Hawaii were omitted because their extreme distance from Florida would make them outliers both in distance and in the small number of older migrants from these states. Three dependent variables were used in the regressions reported here: 1) the natural log of the number of persons over age 55 who migrated to Florida between 1975 and $1980 ; 2)$ the natural log of the number of persons over age 55 who were retired in 1980 and migrated to Florida between 1975 and 1980; and 3) the natural log of the number of persons over age 55 who were retired in 1975 and 1980 and migrated to Florida between 1975 and $1980 .^{3}$ A natural log specification is used here because the flows are approximately log-normally distributed.

Explanatory variables reflect geographic cost of living differentials, the gravity model and amenity factors. These variables were the focus of this investigation of the hypothesis that geographic cost of living differentials provide an economic incentive for the elderly to migrate.
Cost of living in the state of origin for 1980 (COL Origin) was the state wide estimate of cost of living for an elderly couple developed by Fournier et. al. (1988). ${ }^{4}$ The cost of living measure for the 31 county group destinations in Florida (COL Destination) was the annual Florida Price Level Index. 5,6 The coefficient of COL Origin should be positive, suggesting that elderly residents of states with high costs of living are more likely to migrate to Florida than residents of states with low costs of living. The coefficient of COL Destination was expected to be negative; elderly migrants were expected, ceteris paribus, to gravitate to groups of counties with relatively low costs of living.

The gravity model has a simple interpretation. States with larger populations are expected to send more migrants, and relatively populous county groups are expected to receive more migrants. Thus the coefficients of population at the state of origin (POP Origin) and population at the county group destination (POP Destination) were expected to be positive. The gravity model suggests that distance will reduce the migration between two locations. A negative coefficient was expected for the DISTANCE variable, which was the cartesian distance between the geographic center of the state of origin and the center of Florida.

Amenity variables were designed to capture various locational factors that may affect the pattern of migration of elderly people. Several studies have alleged that the elderly are motivated by concerns of safety; this hypothesis was tested by including the number of property crimes per 100,0000 population (CRIME) at both origin and destination. ${ }^{7}$ Climatic differences for states of origin and counties of destination are reflected in the average number of days per year with subfreezing temperatures (CLIMATE). For Florida an indicator variable was also used to identify county groups that are located on the coast and below an arbitrary "frost line" (SUNCOAST). ${ }^{8}$ As a potential measure of leisure amenities and as a proxy for tourism (TOURISM), the number of motel and hotel beds in the destination county group was included. Tourism can be viewed as enhancing the amount of information that residents of other states have about the potential destination.

Fournier et.al. (1988) found support for the hypothesis that migration of the elderly is motivated in part by a desire for proximity to children and grandchildren. Their "family ties" variable suggests that the flows of elderly people are related to the migration of younger households in a previous period. To test this hypothesis, an explanatory variable, the number of migrants between the ages 18 and 35 in 1965-1970 (FAMIL Y TIES), was included.

Ordinary least squares regressions for the three dependent variables employed in this study are presented in Table 1. Since the results were invariant with respect to 
Table 1

Ordinary Least Squares Regressions on Elderly Migrants: Truncated Sample of Positive Flows 1975-1980

\begin{tabular}{|c|c|c|c|}
\hline \multirow[t]{2}{*}{ Independent Variables ${ }^{2}$} & \multicolumn{3}{|c|}{ Dependent Variables } \\
\hline & DEP $1^{b}$ & DEP $2^{c}$ & DEP $3^{d}$ \\
\hline \multirow[b]{2}{*}{ Constant } & & es in parar & \\
\hline & $\begin{array}{r}-6.704 \\
(-3.34)\end{array}$ & $\begin{array}{l}-7.264 \\
(-3.34)\end{array}$ & $\begin{array}{r}-6.823 \\
(-3.24)\end{array}$ \\
\hline LnDistance $^{e}$ & $\begin{array}{r}-.591 \\
(-478)\end{array}$ & -.611 & $\begin{array}{r}-.353 \\
(-270)\end{array}$ \\
\hline \multirow{2}{*}{ Ln Origin Population } & .240 & $\begin{array}{r}(-4.00) \\
.218\end{array}$ & .149 \\
\hline & $(2.63)$ & $(2.25)$ & (1.53) \\
\hline Ln Destination Population ${ }^{\mathrm{f}}$ & .360 & .385 & .419 \\
\hline \multirow{3}{*}{ Cost of Living at Origins } & $(5.23)$ & $(5.21)$ & (5.81) \\
\hline & .088 & .085 & .067 \\
\hline & $(10.02)$ & $(9.09)$ & $(7.45)$ \\
\hline \multirow{2}{*}{ Cost of Living at Destination ${ }^{8}$} & -.079 & -.075 & -.063 \\
\hline & $(5.23)$ & $(5.21)$ & (5.81) \\
\hline \multirow[t]{2}{*}{ Ln Crime at Origin ${ }^{\mathrm{h}}$} & -.155 & -.060 & -.117 \\
\hline & $(-1.23)$ & $(-.44)$ & $(-.87)$ \\
\hline \multirow[t]{2}{*}{ Ln Crime at Destination ${ }^{\mathrm{h}}$} & -.075 & -.102 & -.084 \\
\hline & $(-9.30)$ & $(-9.06)$ & $(-7.87)$ \\
\hline \multirow[t]{2}{*}{ Ln Climate at Origin ${ }^{\mathrm{i}}$} & .682 & .693 & .612 \\
\hline & $(8.69)$ & $(8.32)$ & $(7.48)$ \\
\hline \multirow[t]{2}{*}{ Ln Climate at Destination ${ }^{\mathrm{i}}$} & -.366 & -.372 & -.312 \\
\hline & $(-9.30)$ & $(-9.06)$ & $(-7.87)$ \\
\hline \multirow[t]{2}{*}{ South Coast $\mathrm{t}^{\mathrm{j}}$} & .144 & .075 & .135 \\
\hline & $(1.52)$ & $(.77)$ & $(1.44)$ \\
\hline \multirow[t]{2}{*}{ Ln Tourism at Destination ${ }^{k}$} & .092 & .068 & .026 \\
\hline & $(1.23)$ & $(.88)$ & $(.34)$ \\
\hline \multirow[t]{2}{*}{ Ln Young Migrants ${ }^{l}$} & .487 & .468 & .514 \\
\hline & $(4.74)$ & $(4.31)$ & (4.67) \\
\hline$R^{2}$ & .56 & .54 & .52 \\
\hline $\mathbf{N}$ & 868 & 816 & 747 \\
\hline
\end{tabular}

Variable Definitions

a. Values of $\mathrm{Ln}$ variables were expressed in natural logarithms.

b. DEP1 was expressed as the natural log of the number of persons over age 55 who migrated to Florida between 1975 and 1980.

c. DEP 2 was expressed as the natural log of the number of persons over age 55 who were retired in 1980 and migrated to Florida between 1975 and 1980.

d. DEP 3 was expressed as the natural log of the number of persons over age 55 who were retired between 1975 and 1980 and migrated to Florida between 1975 and 1980.

e. Distance was defined as the Cartesian distance from the geographic center of the state of origin to the geographic center of Florida. f. Population was defined as the 1975 population of the state of origin and of the destination county group in Florida.

g. Cost of living estimates were 1980 state wide estimates for states of origin and 1980 Florida price level indices for Florida counties. $\mathrm{h}$. The crime index was the natural log of the number of property crimes per 100,000 population in 1975 , for both state of origin and county group destination.

i. The climate index was the natural log of the average number of days per year with subfreezing temperatures, for both state of origin and county group destinations.

j. South Coast was defined as the Florida Counties located on the coast below and arbitrary "frost line".

k. Tourism at the destination was expressed as the natural log of the number of hotel and motel beds in the county group in 1980.

1. The young migrants variable was expressed as the natural $\log$ of the number of person aged 18 to 35 who migrated from state $i$ to county group $\mathrm{j}$ during $1965-1970$. 
the choice of dependent variable, the discussion is focused on DEP 1, the natural log of the number of persons over age 55 who migrated to Florida between 1975 and 1980. The sample used in Table 1 is limited to combinations of states and Florida county groups that had positive flows of elderly migrants during the period. 9 For DEP 1 the regression model explained 56 percent of the variation in the flow of elderly migrants. The cost of living at both origin and destination was highly significant: elderly migrants were more likely to leave states with a high cost of living and were more likely to move to Florida areas with a low cost of living.

The gravity model variables were highly significant with the expected sign. Other things the same, larger elderly populations at origin and destination were associated with greater migration flows, while the flows were smaller as the distance between origin and destination increased. Climate was by far the most significant amenity affecting the migration of the elderly to Florida. The flow of elderly migrants was higher from colder states and they were attracted to warmer areas in Florida. The SOUTHCOAST variable had the expected positive sign but it was not significant at customary test levels. The CRIME and TOURISM variables did not have significant impacts on the flow of elderly migrants. Finally, the FAMILY TIES hypothesis was confirmed by the results, at the 0.01 level of significance.

These results are robust in regressions on the other dependent variables and over a broad variety of model specifications. For the purposes of this study, it is most important to emphasize the highly significant effect of cost of living on migration of the elderly. To gauge the impact of cost of living on the migration of older people, the effect of a change in the cost of living when all other variables in regression DEP 1 were set equal to their means was calculated. In this manner, the estimated flow of elderly migrants to the mean county group was calculated to be 486 persons. When the cost of living at the destination was reduced by one standard deviation, approximately 3.2 percent in the sample, the predicted migration flow was increased 9.5 percent to 532. Similarly, when the cost of living at the origin was increased by one standard deviation, about 5.2 percent, the predicted flow of elderly migrants rose to 581 , a 19.5 percent increase. ${ }^{10}$ Thus, on average the estimated effects of COL on migration were quite substantial.

\section{Choosing Among Alternative Destinations}

The above model estimates the influence of variations in interstate and intrastate costs of living on the number of elderly persons migrating to substate areas in
Florida. The effect of intra-Florida cost of living differences on the apportionment among county groups of a given number of elderly migrants was also investigated. A probit model was used to estimate the probability that a. county area would be chosen once the migrant had decided to move to Florida.

To model this question, let $\mathrm{P}_{\mathrm{ij}}$ be the probability an elderly person i moving to Florida will choose county area $\mathrm{j}$ as the destination. Three dependent variables were employed. The data came from the Public Use Microdata Samples for 1975-1980. It was assumed that the discrete choice of county could be expressed in the following form:

$$
\begin{gathered}
P_{i j}=X_{j} b+u_{i j} \\
i=1, n j=1,31
\end{gathered}
$$

where $\mathrm{X}_{\mathrm{j}}$ contains the county area costs of living estimated by the FPLI and other destination variables used in the flows analysis. These include Climate, Tourism, Crime, and SouthCoast. The errors were assumed to be normally and independently distributed. The total number of elderly migrants to Florida during $1975-1980, n_{i}$, the number that migrate to county area $j, m_{j}$, and the explanatory variables can be observed. Thus the model is equivalent to a probit model with the data grouped by county area, and the log likelihood function is

$$
\operatorname{LnL}=n_{i}^{*} \log F\left(X_{i^{\prime}}, b\right)+\left(n^{i}-m^{i}\right) *\left(1-\log F\left(X_{i}, b\right)\right)
$$

where $F($.$) is the standard, normal cumulative den-$ sity function.

The maximum likelihood estimates provided by the model are reported in Table 2. That the model has very good explanatory power is shown by the reported likelihood ratio test. As in the case of flows of elderly migrants, the results were invariant to the choice of dependent variable. All variables in each regression had the expected sign and were significant at customary test levels. Consistent with previous results, cost of living had a significant negative impact on the probability of inmigration to a county area in Florida. The implied elasticity associated with the cost of living (6.8) indicates that when the cost of living in the "median" county group increases by one percent, the predicted probability of selecting the county group falls from 2.22 percent to 2.07 percent.

It should be noted that the elasticity of inmigration with respect to changes in the cost of living varies among county groups. Nevertheless, the analysis suggests that the decisions of elderly people to move to a particular area are highly responsive to the variations in real income that accompany differences in the cost of living. 
Table 2

Probit Regressions on Elderly Migrants to 31 Florida County Groups, 1975-1980

\begin{tabular}{|c|c|c|c|}
\hline \multirow[t]{2}{*}{ Independent Variables ${ }^{2}$} & \multicolumn{3}{|c|}{ Dependent Variables } \\
\hline & $\mathrm{DEP} 1^{\mathrm{b}}$ & $\mathrm{DEP} 2^{\mathrm{c}}$ & DEP $3^{d}$ \\
\hline \multirow{3}{*}{ Constant } & & ues in para & \\
\hline & -0.584 & 0.360 & 0.215 \\
\hline & $(-1.99)$ & (11.21) & $(5.31)$ \\
\hline \multirow[t]{2}{*}{ Cost of Living ${ }^{e}$} & -.034 & -.037 & -.037 \\
\hline & $(-96.82)$ & $(-97.08)$ & $(-76.28)$ \\
\hline \multirow[t]{2}{*}{ Ln Climate $^{f}$} & -.195 & -.203 & -.192 \\
\hline & $(-228.65)$ & $(-217.91)$ & $(-164.54)$ \\
\hline \multirow[t]{2}{*}{ Ln Travel } & .235 & .229 & .244 \\
\hline & $(255.13)$ & $(225.90)$ & (192.07) \\
\hline \multirow[t]{2}{*}{ Ln Crime } & -.046 & -.048 & -.053 \\
\hline & $(-19.02)$ & $(-18.34)$ & $(-16.32)$ \\
\hline \multirow[t]{2}{*}{ SouthCoast ${ }^{\mathrm{h}}$} & .236 & .233 & .224 \\
\hline & $(129.34)$ & $(117.16)$ & (90.11) \\
\hline Log-likelihood $\left(\times 10^{-2}\right)$ & $-26,173.0$ & $-21,958.0$ & $-13,986.0$ \\
\hline
\end{tabular}

Variable Definitions

a. Values of $L n$ variables were expressed in natural logarithms.

b. DEP1 was expressed as the natural log of the number of persons over age 55 who migrated to Florida between 1975 and 1980.

c. DEP 2 was expressed as the natural log of the number of persons over age 55 who were retired in 1980 and migrated to Florida between 1975 and 1980.

d.DEP 3 was expressed as the natural log of the number of persons over age 55 who were retired between 1975 and 1980 and migrated

to Florida between 1975 and 1980.

e. Cost of living estimates were 1980 Florida price level indicies for Florida counties.

$f$. The climate index was the natural log of the average number of days per year with subfreezing temperatures.

g. The crime index was the natural log of the number of property crimes per 100,000 population in 1975.

h. South Coast was defined as the Florida counties located on the coast below an arbitrary "frost line".

\section{Conclusions}

Thousands of elderly persons migrate to Florida every year. Yet their choices of location within the state are little understood. Better predictions of the destinations of these migrants are essential for the provision of population projections that are adequate for sound planning of infrastructure needs and delivery of social services. Two questions must be addressed if improved population projections are to be realized: 1 ) what factors determine the destinations of elderly migrants? and 2) how important are geographic variations in cost of living for location decisions? These questions are addressed in the research.

Modelling the destination choices of elderly migrants among intrastate locations is a pathbreaking effort because most studies rely on aggregated state data and few researchers have considered the impact of variations in the cost of living.
Several studies have speculated that cost of living differentials might provide an incentive for elderly persons to move from places with relatively high costs of living. Fournier et. al. (1988) used flows of elderly migrants among the 48 states to provide the first rigorous test of this proposition. Although that study found a strong relationship between flows of elderly migrants and the estimated cost of living, such state-wide control variables as those designed to reflect amenities necessarily were crude and sometimes had unexpected signs. The data used in this study permit better control of the amenity variables since the intrastate destinations are more homogeneous than entire states. ${ }^{11}$ The results confirm that the migration decisions of the elderly really are sensitive to cost of living variations.

These results obviously are important for forecasting elderly populations in order to plan service delivery systems and infrastructure needs. Estimates of the elderly 
population that are driven by age cohorts and constant migration rates (such as the U.S. Census estimates) implicitly assume that relative costs of living will remain constant over time. Since differential rates of growth can affect relative costs of living among geographic areas, the results of this study suggest that it is perilous to forecast the elderly population of small geographic areas under the assumption of constant migration rates.

\section{Notes}

${ }^{1}$ McLeod et. al. (1984), Rives et al. (1983) and Fournier et. al. (1988) have employed variables reflecting these factors to study the flow of elderly migration. Studies of net migration (e.g., Cebula, 1979) employ only amenity and economic variables. Alperovich (1979), Cebula $(1981,1982)$ and Renas and Kumar (1981) all discuss the impact of cost of living variations on the migration of the elderly.

${ }^{2}$ Migration data in the 1980 Public Use Microdata sample are available for 20 of the 67 Florida counties, with the remaining 47 counties included in 11 multiple county groups. These 31 geographic areas are termed county groups.

${ }^{3}$ When the analysis of older migrants includes all persons over 55 years old there is the possibility that labor market considerations were significant for a number of migrants who remained in the labor force. In order to eliminate this problem, the analysis was expanded to consider the migration behavior of retired migrants. There were 13,648 migrants to Florida over age 55 between 1975 and 1980. Of this number, 11,415 were retired in 1980 and 7,266 were retired in both 1975 and 1980.

This index of geographic cost of living differentials is a statistical estimate created from the U.S. Bureau of Labor Statistics budget survey for elderly households. Fournier et. al. (1988) report that their cost of living estimates were corroborated by independent evidence available for cities in Virginia and counties in Florida.

SThe Florida Price Level Index (FPLI) is computed by the Department of Administration of the State of Florida for each county in the State. There are 135 items on the 1980 index. The expenditure weights used are identical to or some combination of those for urban wage earners and clerical workers in Miami as computed by the U.S. Bureau of Labor Statistics. The computed FPLI values used here are relative to the state average value of the weighted prices from the various counties; hence the average value for the state is 100 . The value of the FPLI for a particular county depends on the deviation of the sum of weighted prices for that county from the state average. When there is more than one county in a group two COL Destination variables were created. The first, which is reported in the text, weights the individual county FPLI by the proportion of the county population of the group residing in that county. The second measure is a simple average FPLI for the counties in the group. The results are insensitive to the choice between these measures.
'There was considerable variation in the Florida Price Level Index among the 31 groups of counties. Monroe County had the highest index (106.24); the lowest index was in a northeastern county group (93.86). This represents a 13 percent differential. .

The availability of medical care, as measured by the number of physicians per capita, also has been employed in models of the migration of elderly persons. In state studies (e.g., Fournier et. al. $1986,1988)$ this variable generally is insignificant and sometimes has an unexpected sign. Inspecting these data for the Florida county groups revealed that this variable is highly correlated with population. It appears that once a quality threshold of medical care is reached in an area, variations in normal measures of availability are not an important determinant of migration. For these reasons this variable was omitted from the analysis.

"The "sun coast" is comprised of coastal counties south of Brevard County on the Atlantic Ocean and Pinellas County on the Gulf of Mexico.

There are 1457 possible flows from 47 states to 31 county groups in Florida, although the flow is trivial for a large number of these. The analysis reported here includes only those combinations of states and county groups that had positive flows of migrants. This procedure was deemed appropriate, given the focus on observable migration, to avoid the effects of including a large number of zero flows on the estimated coefficients. When all 1,457 observations were used the results were similar but the coefficient of determination was somewhat higher. The coefficients of specific interest, those for cost of living, were larger and more significant when the whole sample was used.

${ }^{10} \mathrm{~A}$ good measure of the explanatory power of variations in $\mathrm{COL}$ is the "beta coefficient," which measures the change in the explained variable accounted for by a unit change in the explanatory variable, in units of standard deviation (Maddala, 1977, p. 119). The beta coefficients for cost of living at the origin and destination were 0.35 and -0.19 , respectively.

${ }^{11}$ Caution is advised in extending the results presented here to destinations in other states. Florida has some unique characteristics, e.g., its large tourist population that suggest the presence of unspecified amenity factors. Nevertheless, it is reasonable to expect that the general pattern of responsiveness of migration rates to variations in costs of living would be found in wellspecified models estimated for other locations.

\section{References}

Alm, James, 1982. "State Government Fiscal Choices and Individual Mobility," Southern Economic Journal 48: 877 92.

Alperovich, Gershon, "The Cost of Living, Labor Market Opportunities and the Migration Decision: A Case of Misspecification? Comment." The Annals of Regional Science, Vol. XIII, No. 3, November 1979, pp. 102-105.

Barsby, Steve L. and Dennis R. Cox, 1975. Interstate Migration of the Elderly: An Economic Analysis. Lexington: D. C. 
Heath.

Cebula, Richard J., "The Cost of Living, Labor Market Opportunities, and the Migration Decision: A Case of Misspecification?: A Comment." The Annals of Regional Science, Vol. XV, No. 3, November 1981, pp. 73-74.

1979. Determinants of Human Migration. Lexington: D.C. Heath.

"Real Earnings and Human Migration in the United States," International Migration Review, Vol. 16, No. 1, Spring 1982, pp. 189-196.

Fournier, Gary M. and David W. Rasmussen, 1986. "Salaries in Public Education: The Impact of Geographic Cost of Living Differentials," Public Finance Quarterly, 14:2, 179-198.

Fournier, Gary M., David W. Rasmussen and William J. Serow, "Elderly Migration as a Response to Economic Incentives," Social Science Quarterly, June 1988.

Greenwood, Michael J., Gary L. Hunt and John W. McDowell, 1986. "Migration and Employment Change: Empirical Evidence in the Spatial and Temporal Dimensions of the Linkage." Journal of Regional Science 26: 223-234.
Heaton, Tim B., William B. Clifford and Glenn V. Fuguitt, 1981. "Temporal Shifts in the Determinants of Young and Elderly Migration in Non Metropolitan Areas," Social Forces 60:4160.

Madalla, George S., 1977. Econometrics. New York: McGraw Hill.

McLeod, Karen, Jan R. Parker, William J. Serow, and Norfleet W. Rives, 1984. "Determinants of State-to-State Flows of ElderlyMigrants," Research of Aging 6:372-83.

Morgan, James N. and Edward H. Robb, "The Impact of Age Upon Interregional Migration,"The Annals of Regional Science, Vol. XV, No. 3., November 1981, pp. 31-45.

Renas, Stephan M. and Rishi Kumar, "The Cost of Living, Labor Market Opportunities, and the Migration Decision: Some Additional Evidence,"The Annals of Regional Science, Vol. XV, No. 3, November 1981, pp. 73-79.

Rives, Norfleet W., William J. Serow, Gary Freeman, and Karen McLeod, 1983. "Migration of the Elderly: Are Conventional Models Applicable?" Proceedings of the American Statistical Association (Social Statistics Section): 343-47. 


\title{
REGIONAL EARNING PATTERNS: NOTE
}

\author{
Edward Nissan
}

\section{Introduction}

A noticeable feature of the U.S. economy in recent years has been the shift in employment and population among regions. The underlying causes may be attributed to many factors operating individually or in combination. These factors include changes in demand for certain manufacturing and agricultural products, energy resources, and services, in domestic as well as international markets. The introduction of new technologies tends to favor location of economic activity in some regions rather than in others. Furthermore, government expenditures and taxes have differential regional impacts.

These changes influence the reallocation of employment and population, and of total regional income and earnings (the sum of wages and salaries, other labor income and of proprietors' income). A booming region registers a higher growth in earning than an economically stagnant region (Garnick 1984, 1985, 1986). Garnick was concerned with the differentials in growth rates of population, total income and earnings in MSA and nonMSA that typify urbanized and less-urbanized regions. The time period of his study 1959 to 1984 , was disaggregated into three segments - 1959-69, 1969-79, and 1979-84.

The purpose of this study is to present a supplementary examination of the findings of Garnick using a portion of his 1986 data. The concern here, however, pertains to regional differentials in total income and earnings in MSA areas across the three time segments and four city sizes.

A summary of the data used herein is reported in Table 1. The values shown for the eight regions defined by the Bureau of Economic Analysis (see Endnotes) are the average growth rates for the cities of the four sizes that comprise the MSAs. The fourcity size groups are less than 0.5 million, 0.5 -to 1 million, 1 to 2 million, and over 2 million. Growth rates are indicated in Table 1 for personal income in column one, earnings in column two, and earnings excluding farming and manufacturing in columns three through five. Earnings excluding farming and manufacturing factor out the impact of these sectors on total earnings.

"Professor of Economics, University of Southem Mississippi

\section{Model Background}

Three components of the model are associated with the growth of total income and earnings: Region $(R=$ $1,2, \ldots, 8)$, Time $(T=1,2,3)$ and MSA size $(M=1,2, \ldots, 4)$. Three-way analysis of variance was used to test the potential effect of each factor on growth. There are three tests to establish significance.

The results of the tests indicate that the Region (R) and Time (T) variables are significant in explaining the variation in growth while MSA size is not. A two way analysis of variance was used as an additional test of the significant variables. Hypothesis 1 states that the growth rate is determined primarily by regional variation. Hypothesis 2 asserts that differences are determined primarily by time variation. To determine whether these variables are interdependent, an interaction component (RXT) was assumed. If there is no interaction between the two variables, the presence of one will not influence the other.

Table 2 provides a summary of the results. The factors under consideration are significant in all cases as indicated by observing the values of the F-ratios and comparing them with the theoretical F-distribution with the appropriate degrees of freedom. These are: $F(0.01 ; 7,69)$ equals $2.91 ; F(0.01 ; 2,69)$ equals 4.92 ; and $F(0.01 ; 14,69)$ equals 2.35 , where 0.01 is the significance level of the test and the two succeeding numbers are the degrees of freedom.

A conclusion can be drawn by observing theF-ratios in Table 2, that time is the more important variable. The influence of time regional differentials in growth rates is very evident. For hypothesis testing, a significant F-test implies the rejection of equality of regional growth rates over time. A third analysis was undertaken to identify groups of regions that do not differ significantly. A multiple comparison procedure was used to compare all possible pairs of growth rates. Pairs that do not differ significantly were grouped in identifiable subsets. The results and analysis follow in the next section.

\section{Empirical Results}

Several procedures are available for examining the homogeneity of growth rates. The method used here is due to Newman and Keuls (Ostle and Malone, 1988, p. 189). 